\title{
O PROCEDIMENTO DELEUZIANO DE CRIAÇÃO: APORTES PARA PENSAR O CURRÍCULO (DE MATEMÁTICA)
}

Virginia Crivellaro Sanchotene*

Samuel Edmundo Lopez,Bello**

\begin{abstract}
RESUMO: Este artigo discute a potência da maneira singular com que Deleuze realiza a leitura dos autores que lhe afetaram, nas torções que realizou ao expandir tais leituras na produção de seus conceitos. Deleuze lê e procede por corte, colagem e criação que funcionam por arranjamento e conexões de variáveis, próximo de um algebrista que estabelece relações entre partes distintas. Defendemos aqui que este modo de ler-e-manipular pode servir à leitura do Currículo maior, oficial, a fim de criar brechas docentes de minorização. Desse modo, questionamos o Currículo (de matemática) hegemônico, que visa à padronização de comportamentos e à utilidade como valor do conhecimento.
\end{abstract}

PALAVRAS-CHAVE: Minorização. Currículo. Deleuze. Docência. Matemática.

\section{THE DELEUZIAN PROCEDURE OF CREATION: CONTRIBUTIONS TO THINK ON TEACHING AND THE (MATHEMATICS) CURRICULUM}

\begin{abstract}
This article discusses the power of the singular way in which Deleuze performs the reading of the authors who affected him, through the deviations he made when expanding such readings in the production of his concepts. Deleuze reads and proceeds by cutting, pasting, and creating, that work by arranging and connecting variables, close to an algebraist who establishes relationships between distinct parts. We argue here that this way of reading-and-manipulating can serve to the reading of the larger, official, curriculum, in order to create teaching gaps of minorization. Thus, we question the hegemonic (mathematics) curriculum, which aims at the standardization of behaviors and at utility as the value of knowledge.
\end{abstract}

KEYWORDS: Minorization. Curriculum. Deleuze. Teaching. Mathematics.

* Doutoranda em Educação pela Faculdade de Educação da Universidade Federal do Rio Grande do Sul; e-mail vicrivellaro@hotmail.com; ORCID 0000-0001-7083-0622

** Doutor em Educação (UNICAMP) e professor da Faculdade de Educação da UFRGS, e-mail samuelbello40@g,gmail.com; ORCID $\underline{0000-0002-3857-9121}$

\begin{tabular}{|l|l|l|l|l|l|}
\hline APRENDER - Cad. de Filosofia e Psic. da Educação & Vitória da Conquista & Ano XV & n. 25 & p. 109-120 & Jan./Jun. 202
\end{tabular}


Deleuze criou uma maneira singular de leitura dos autores que lhe afetaram, o que pode ser percebido nos livros que lhes dedicou - Kafka, Bacon, Espinosa, Leibniz, Proust, Nietzsche, Foucault, entre outros -, realizando torções ao expandir tais leituras na produção de seus conceitos. Deleuze lê e procede por corte, colagem e criação. Sua leitura é produtiva: produz torções, efeitos, conceitos - função esta que atribui à filosofia. Sua leitura é estratégica, distanciando-se de uma hermenêutica que perguntaria “o que este autor quis dizer?” e aproximando-se de uma política experimental que questiona "quais os efeitos disso que leio?”.

Interessa-lhe o funcionamento da máquina literária, a força do texto, suas intensidades, transformações, rupturas, linhas de fuga. Sua leitura se faz texto através de um procedimento de atualização que produz dobras, velocidades, desterritorializações, por criação. Deleuze opera ao modo de um algebrista, estabelecendo conexão entre variáveis, entre partes que a princípio não se comunicavam, entre elementos distintos dispostos no campo do possível, dando-lhes corpo através do processo de atualização. Ele reúne e partilha, manipula, intervém: sua leitura não é pacífica, é máquina de guerra, exige intervenção naquilo que é lido, maquinação feita por criação. Seus conceitos são efetuações de pontos singulares dispersos, diferençados num trabalho de experimentação e criação. Em Diferença e Repetição (2006), Deleuze estabelece o duplo diferenciação e diferençação como as duas metades dessemelhantes de toda coisa: a diferenciação ao lado da virtualização, da intensidade, da multiplicidade; e a diferençação, ao lado da atualização, da integração, da resolução. A diferençação exprime a atualização das singularidades virtuais.

Fazer emergir do texto interpretações que não estão dadas a priori, promover ocupações - em trânsito - em seus vazios e engendrar maquinações por derivação rompe com a soberania do significado, com a pretensa universalização metafísica do sentido e sua ambição totalizante, com a promessa de uma verdade da obra e com a possibilidade de um acesso à intencionalidade primeira que a constituiu. $\mathrm{O}$ sentido, na operação deleuziana de apropriação, corte, colagem e criação, não está dado, à espera de seu desvelamento pelo leitor. O sentido se constrói por relação. O texto é um lugar de investimento, exige um debruçar-se sobre, um trabalho, uma postura - que Deleuze realiza ao ler seus intercessores e que a leitura de seus livros exige e que, neste artigo, sugerimos ser uma maneira de ler o Currículo. Destacamos que ler, aqui, está intimamente ligado a pensar, discutir, manipular, rachar e agir sobre.

É nesse sentido que sugerimos ler o Currículo e, assim, movimentar nossa docência e nosso planejamento, bem como a efetivação de uma aula (de matemática): operacionalizando por apropriação, corte, colagem e criação; tomando a aula como lugar de investimento e experimentação; estando atendo à força do que ali acontece, suas intensidades, humores, velocidades, rupturas e linhas de fuga. Deseja-se a leitura dinâmica dos vazios, dos desvios e das rupturas dos saberes, dizeres, olhares, viveres que ali se encontram. 
Para a elaboração deste tema, inspiramo-nos, além deste procedimento deleuziano que expusemos acima, nos conceitos de estilo e literatura menor, ambos pela ótica de nossa leitura - e, portanto, nosso procedimento de dobrar o texto - de Deleuze e Guattari. O estilo não se refere a uma criação psicológica individual, mas a um agenciamento de enunciação (DELEUZE, GUATTARI, 1995, p. 41). Trata-se de uma variação contínua, de um empreendimento de criação de uma língua dentro da própria língua, como a gagueira ou, colocando em forma de ação, como o gaguejar, que instala um deslocamento na ordem vigente do "bem falar" ou, aplicado ao texto, do "bem escrever".

Assim como "há modelos que povoam o senso comum e o bom senso do que seria a correta forma do escrito" (MALUFE, 2010, p. 104), há modelos que ditam e normatizam uma boa aula ou o bom professor de matemática. O estilo opera, então, "uma subversão, uma transgressão às leis gramaticais, estando mais próximo do erro do que do acerto, do desvio do que da norma" (MALUFE, 2010, P. 99). O estilo se constrói, não está pronto e não é definitivo. O caminho percorrido se distancia de valores instituídos no campo da Educação Matemática, fabricados e fortalecidos por processos de mensuração de conhecimento, classificação de sujeitos e nivelamento de saberes. Não abraça, portanto, verdades discursivas que orientam uma conduta para o bom professor de matemática ${ }^{1}$ ao proclamarem o uso pedagógico da realidade do aluno, ao forjarem identidades docentes utilitaristas, contextualizadoras, lúdicas ou tecnológicas ${ }^{2}$. A matemática, como um recorte de conhecimentos do qual a instituição escolar faz uso, não é tomada como um campo de saber neutro, proveniente de uma essencialidade, mas como um campo disciplinar de conhecimentos arquitetados por coletividades, em solos moventes e contingentes.

Propõe-se uma aula (de matemática) planejada e efetivada por intensidades, por estados do desejo, como caminho. Caminho que se faz pelo caminhar, por extravios, afastamentos, encontros, inflexões, sobras, cortes, curvas, deslizes: (des)caminhos. Nesse sentido, distanciar-se da ação mimética que prevê a repetição sem criação, sem excedência, sem diferença, bem como da linearidade de currículos hegemônicos. Deseja-se a minorização de um currículo (matemático) e a elaboração estratégica de um estilo como procedimentos políticos e estéticos de leitura - e escrita - da aula (de matemática).

\section{Minorar um Currículo (de Matemática)}

Partindo do conceito de devir-menor desenvolvido por Deleuze e Guattari (1995), colocamo-nos a pensar sobre a minoração de um currículo (de matemática). Um devir menor no currículo tem sido pensado como força de desacomodação diante do Currículo vigente, de subverter modelos estruturados,

\footnotetext{
${ }_{1}^{1}$ Sobre isso, Grace da Ré Aurich desenvolveu uma pesquisa sobre jogos de verdade na constituição do bom professor de matemática, em meio a "discursos, saberes, experiências e relações de poder que as instituem e regulam", através de instrumentos normalizadores de condutas (Aurich, 2018, p. 105).

${ }^{2}$ A esse respeito, Gilberto Santos nos apresenta identidades docentes que se legitimam na interpretação de discursos oriundos da Educação Matemática, forjando o uso pedagógico da realidade (Santos, 2018).
} 
institucionalizados, normativos (GALLO, 2002; GALLO, 2013; ROSA, 2016). Faremos o percurso de adentrar no conceito de devir-menor, para então movimentar o pensamento sobre a possibilidade de traduzir a minoração de um currículo para o campo da Educação Matemática.

Minorar não é pensado como quantitativo, não se trata de aritmética. Minorar é visto como desvio, como (des)caminho dos modelos institucionalizados de existência e conduta. O menor insurge como positivação do que diverge, do que é parcial e fragmentário. "Não há nada tão grande, nem revolucionário, quanto o menor” (DELEUZE, GUATTARI, 2017, p.52).

O Currículo, escrito com artigo definido e grafado com letra maiúscula, condicionado às leis, normas, prescrições, molarizado, duro, estanque, assegurado por formações de professores iniciais e continuadas, livros didáticos e diversos outros aparatos de governamento, é tomado aqui como o currículo maior, aquele que se pretende universal. Um currículo pronto a ser seguido é como a rocha de Sísifo, que impõe ao professor um trabalho rotineiro e cansativo.

Desejar e operar um currículo menor não surge como um outro polo que serviria à representação na constituição de mais um binarismo que opõe Bem e Mal, certo e errado, ciência e arte, porque não existe um currículo menor a priori que possa contrapor-se ao Currículo. Ele não está dado, não está disposto como um outro lado da moeda curricular. Minorar um currículo é infiltrar-se na estrutura que sustenta o Currículo e, ali, cavar brechas. Trata-se de romper com expectativas, frustrar demandas prontas, quebrar a linearidade. "Nesse sentido, a maioridade é condição de existência de uma dada menoridade" (ROSA, 2016, p. 687).

Ao se referirem à língua maior e menor, nos dizem Deleuze e Guattari que “umas se definiriam precisamente pelo poder das constantes; outras, pela potência de variação. Não queremos simplesmente opor a unidade de uma língua maior a uma multiplicidade de dialetos" (1995, p. 47), pois "não existem dois tipos de língua, mas dois tratamentos possíveis de uma mesma língua” (1995, p. 49). Assim, “'maior” e 'menor' não qualificam duas línguas, mas dois usos ou funções da língua” (DELEUZE, GUATTARI, 1995, P. 50).

Com isso, não acreditamos que haja um currículo menor. Existe e está dado o Currículo. E, a partir do que fazemos com o que está disposto, através de procedimentos de apropriação, corte, colagem e criação, através de encontros e rupturas, através de um tratamento, um labor, operamos uma minorização curricular. Nesse sentido, não existe um currículo menor enquanto documento, parâmetro, diretriz, lista, orientação, institucionalização de saberes e dizeres mais verdadeiros ou legitimados - ou verdadeiros porque legitimados. Existe a ação estratégica, a maquinação de minorar o Currículo, isto é, uma maneira de "colocar o currículo em variação contínua, submetê-lo a um tratamento menor para reencontrar as potencialidades de vida e pensamento” (MUNHOZ, ADÓ, 2017, p. 153).

Consideramos um currículo como um espaço privilegiado de discussão de saberes, metodologias, procedimentos. Conceber um currículo como movente e plástico distingue-se de elaborar uma lista fixa de conteúdos e prescrições; não obriga um modus operandi docente calcado em paradigmas cartesianos, 
numa visão em que se faz necessário fragmentar para conhecer, unir as partes menores para aquisição de saberes supostamente mais complexos; não se trata de consenso e não hierarquiza saberes.

Um currículo concebido nas filosofias da diferença, considera a escola como lugar de produção de novidade e estranhamentos, compreendendo que aprender e desaprender se inscrevem no mesmo processo. Considera-se que a aprendizagem não é uma passagem do não sabido ao saber, mas uma troca incessante entre o conhecido e o desconhecido. Pensando esta aprendizagem e estes currículos, elaboramse maneiras de agir que se distanciam dos efeitos massificantes e generalistas sobre sujeitos e saberes, na criação de relações cambiantes e diferenciais.

Consideram-se os currículos como instabilidades, contornando "certa incumbência que coloca o currículo a serviço de uma institucionalização homogeneizante ao selecionar determinados saberes que acabam servindo somente como reprodução que interrompe a produção de singularidades" (ADÓ; CORAZZA; CAMPOS, 2017, p. 1167). Interessam-nos os currículos que consideram o conhecimento como mola propulsora, como composição multidimensional potente, influentes e influenciados por interferências criadoras. Trata-se de pensar um currículo móvel que permite a produção de ficções por áreas.

Currículos olhados como zonas de contágio, de encontros, cujos repertórios são plausíveis de fazerem-se e desfazerem-se, ampliarem-se, modificarem-se, atualizarem-se. Uso as palavras de Haroldo De Campos, deslocando-as para o tema do currículo que aqui interessa: "acrescenta-lhe, como numa contínua sedimentação de estratos criativos, efeitos novos ou variantes" (CAMPOS, 2015, p. 7), em linhas de invenção, “[...] uma operação de crítica ao vivo. Que disso tudo nasça uma pedagogia, não morta e obsoleta, em pose de contrição e defunção, mas fecunda e estimulante [...]” (CAMPOS, 2015, p. 14). Um currículo, como a literatura apresentada pelo autor, como "domínio do simultâneo, um simultâneo que se reconfigura a cada nova intervenção criadora” (CAMPOS, 2013, p. 24).

Em Kafka: por uma literatura menor (2017), Deleuze e Guattari apresentam três elementos de uma literatura menor: "a desterritorialização da língua", "a ligação do individual no imediato-político" e o “agenciamento coletivo de enunciação” (2017, p. 39). Assim, uma literatura menor consiste na prática de uma minoria numa língua maior, modificando-a, achando seu próprio ponto de subdesenvolvimento, um exercício menor de uma língua maior; tudo numa literatura menor é político, onde pormenores individuais tornam-se aumentados ao microscópio em que toda uma outra história nela se agita (DELEUZE, GUATTARI, 2017, p. 36); e, por fim, sua função de enunciação coletiva, uma máquina revolucionária porvir.

Talvez esteja aí uma pista de como operar a minorização do Currículo: através da formulação de práticas estrangeiras dentro do próprio Currículo; a ocupação desse lugar de enunciação que não se direciona ideologicamente, mas politicamente na contramão de blocos sedimentados como o são os comerciais, midiáticos, familiares, burocráticos, econômicos; na invenção de um povo porvir que subverte a lógica do Mesmo, na positivação das multiplicidades que nos atravessam, em detrimento de 
uma Identidade que se pretendia assegurar. "O menor (petite), outrora de dimensão negativa, é transvalorado como algo desejável e portador de devir (WEISSMANN apud ROSA, 2016, p. 688).

Uma atitude de minorização de um currículo não se imita, não acontece por mimetismo: se cria. Inventa-se uma atitude de minorização. Inventariam-se seus procedimentos não a fim de imitá-los $a$ posteriori, mas como recursos a serem manipulados desejando-se outras criações.

\section{Quando a Aula (de Matemática) Não Visa a Utilidade}

Seguindo pistas do que chamamos de procedimento deleuziano de criação, assumimos o desafio propositivo de ler o Currículo, suas necessidades criadas, e dali fazer proliferar um processo de abrir brechas, fendas, desejando uma produção (em aulas de matemática) mais polifônica e polissêmica. Parecenos que uma pista desse procedimento consiste em uma prática de inquirição ao que está posto, não a fim de obter respostas, mas a fim de colocar em movimento uma desconstrução, sabendo que respostas serão datadas e localizadas, parciais e substituíveis. Mas não se trata de fazer interrogações, como nos diz Deleuze, em seu abecedário, entrevista concedida à Claire Parnet, onde na letra Q de Questão ele afirma que nas conversas correntes e na mídia, ficamos ao nível das interrogações. Interrogar, nesse sentido, seria permanecer no campo do já sabido, das opiniões, do senso comum e da doxa.

Consideramos que o exercício de elaborar perguntas demanda um outro olhar, um estranhamento diante do que está dado. Inquirimos ao Currículo qual a potência disso que está proposto? Qual o espaço do caos-errância nessas prescrições? Como articular este Currículo com práticas menores, cotidianas, ínfimas, que nos atravessam? Qual o espaço de composição e tangenciamento com outros saberes, dizeres, olhares, sentires, que esta prática arraigada no disciplinamento nos deixa? Como cavar brechas e permitir a passagem de ar?

Adentrando mais especificamente no Currículo de Matemática - e aqui Matemática também é grafada com letra maiúscula porque se pretende universal - é fácil ver que há sempre uma possibilidade assegurada por documentos oficiais e discursos midiáticos de ensinar matemáticas afirmando seu valor na vida prática ou sua necessidade para o futuro. Em contraposição à Matemática, substantivo, vamos considerar aqui matemáticas, adjetivo que qualifica práticas. Colocamo-nos a elaborar questões: qual o sentido de vida e necessidade aqui e quais outros sentidos não são abraçados? Qual a força disso que chamo de útil e disso que chamo de inútil?

Como docentes de matemáticas, consideramos que essas duas instâncias - o valor na vida prática e a necessidade para o futuro - se apresentam problemáticas. Primeiro, porque a vida não se submete a relações matemáticas de regularidade e padrão. “A um mundo que não seja nossa representação, as leis dos números são inteiramente inaplicáveis" (NIETZSCHE, 2005, p. 29). As matemáticas, como ciências que estudam regularidades, pouco têm a ver como que frequentemente se associa à vida prática - a menos 
que reduzamos esta prática a pagar contas, fazer um bolo... ou seja, a menos que a acepção de regularidade seja submetida à limitação do hábito.

Podemos discutir o sentido de vida: viver não é sobreviver. Viver não é administrar a vida. Viver está mais do lado desse pulsar, desse desejo de ampliação de potência que "está em pleno vir a ser, e por isso não deve ser considerada uma grandeza fixa" (NIETZSCHE, 2005, p. 25). Disso deriva que as matemáticas podem, sim, ter utilidade na vida prática, mas que vida dispensa o adjetivo prática e que utilidade assume outros sentidos.

Podemos, ainda, questionar os sentidos assumidos, aqui, para futuro e utilidade. Um conhecimento legitimado como útil para o futuro (para a série seguinte, para o Exame Nacional do Ensino Médio, para o vestibular, para a administração da vida) não é considerado útil, necessariamente, para desmontagens parciais daquilo que se é e constituir-se outro, sempre provisoriamente. Ou seja, não é obrigatoriamente útil ao movimento e à variação próprios da vida, mas a instâncias e aparatos de governamento que servem como sustentação a práticas de mimetização, hierarquização de saberes e classificação de sujeitos.

A promessa da utilização de um determinado saber numa experiência futura acaba por constranger possibilidades de aprendizagens tomadas como mobilizadoras de si, como ferramentas de interpretação de mundo, como propulsoras de modos de estar no mundo, por criação. Deseja-se a inflexão sobre a utilidade do conhecimento: considerar úteis saberes contingenciais, relacionais, arbitrários, que por vezes intersectam o conjunto de conhecimentos historicamente legitimados como necessários, mas que de maneira alguma coincide com ele. Sugere-se que o conhecimento se aproxime de um caráter poético, no sentido de diferenciar-se de um fim utilitário, aproximando-se de um fazer, de um labor, um trabalho artesanal compositivo.

Nietzsche (2011, p. 250) nos apresenta que aquilo que chamamos de utilidade é apenas uma crença e, "talvez, precisamente a fatídica estupidez da qual um dia pereceremos". Tomar o caráter utilitário do conhecimento diminui o dinamismo próprio à produção do pensamento. "Supondo que em todas as épocas venerou-se a utilidade como a divindade suprema, de onde teria vindo a poesia?" (Nietzsche, 2011, p. 111).

Nas matemáticas, há conhecimentos que são produzidos como experimentações de pensamento, sem visar uma aplicação utilitária. Machado (2011) nos traz como exemplo a Agulha de Buffon, problema do século XVIII lançado pelo Conde francês que dá seu nome à questão, que consiste, de maneira mais elaborada do que apresentamos aqui, nas chances de uma agulha lançada ao acaso sobre um papel cortar uma das retas riscadas nele ou cair situando-se completamente entre duas delas. Laplace, um século depois, encontrou uma aplicação considerada útil ao problema, no cálculo de probabilidades para determinar comprimento de curvas ou áreas de superfície, conduzindo a uma maneira de calcular aproximações para $\pi$ (número PI). O autor destaca que "a aplicabilidade refere-se sempre a um período historicamente situado [...] e, frequentemente, tal noção tem-se revelado leviana, volúvel ou volátil” (2011, p. 73). Disso, decorrem riscos de ensinar apenas aquilo para o qual se encontra efetiva aplicabilidade. 
Nietzsche, em Humano, demasiado bumano, nos traz uma citação de Horácio, evocando sua frivolidade, em que o poeta pergunta: "Por que afadigas a alma pequena com desígnios eternos?" (2005, p. 80). Questionam-se, desse modo, as possibilidades e as consequências de desejar o infinito e o eterno, na tentativa de suprimir o imprevisível e o contingente, estes, sim, constitutivos dessa mobilidade inerente à vida.

Tornamo-nos humanos, demasiadamente humanos, a partir de conformações e moldagens engendradas culturalmente e de reações que arrefecem instintos, paixões e arrebatamentos, mas também em meio a combates que operam desmontagens, uma "maneira de ser guerreira" (Nietzsche, 2010, p. 37), rompendo a teia tecida em torno de si, fios que se tornam cordas por meio dos hábitos e das regras. Essa operação guerreira, modo outro de conduzir-se humano, gera "feridas inúmeras, pequenas ou grandes" (Nietzsche, 2005, p. 209), mas produzem modos ético-estético-políticos de alargamento de vida.

Enquanto a maioria, este "homem-branco-masculino-adulto-habitante das cidades-falante de uma língua padrão-europeu-heterossexual” (DELEUZE, GUATTARI, 1995, p. 52), implica uma constante ou um metro padrão sobre o qual se realizam as práticas de avaliação, o devir-menor, um potencial criador e criativo, possibilita pensar rupturas com o paradoxo legislador-sujeito, esta nova forma de escravidão que é ser escravo de si mesmo (DELEUZE, GUATTARI, 1995, p. 85), este culto à identidade e à normatização.

Esta pesquisa, este olhar para o Currículo e para a aula, se faz em meio à filosofia deleuziana da diferença, afirmando a dessemelhança e o díspar, abraça o acaso, o múltiplo, o devir. O acaso é tomado como imanente à vida - porque a vida é considerada uma zona de indeterminação, força plástica, solo movente. Deleuze (2006) nos apresenta que a identidade não existe como princípio, ela é algo tornado princípio. O mundo da vontade de potência, da dissolução de identidades prévias, do caos-errância, impõe à vida finita um movimento infinito e impossibilita padrões de normatização de sujeitos e hierarquização de saberes. Esse movimento é infinito e infinitesimal, porque não se encerra e não ganha importância em proporção à quantidade de deslocamento que produz. "Com relação ao pequeno, não há um mínimo, mas há sempre um menor, porque o que existe não pode ser anulado” (ABBAGNANO, 2015, p. 646).

Não considerar a diferença como conceito reflexivo, mas proveniente de rupturas parciais da forma em si mesma, ou ainda, algo que se distingue ao mesmo tempo em que aquilo do qual ele se distingue não se distingue dele (DELEUZE, 2006, p. 55), implica a suspensão da identidade que visa igualar o desigual, como fundamento ontológico - esta identidade criada, tomada como primeira, que relega a diferença a segundo plano. Afirma-se a diferença pura, em que o que difere não esteja subordinado ao Uno, ao Análogo, ao Semelhante ou mesmo ao Negativo (DELEUZE, 2006). Desse modo, uma docência em meio à diferença pura implica abraçar o caótico e o nômade que compõem toda forma, investindo no movimento que é próprio de toda a coisa. Nesse sentido que adentramos ao Currículo e, por um exercício de desmontagem, questionamo-lo e cavamos brechas. 


\section{O Procedimento Deleuziano de Criação}

Quando dizemos que o procedimento que Deleuze realiza para a elaboração de seus conceitos e para sua escrita opera por acumulação, corte, colagem e criação, ao modo de um algebrista, distanciamonos de uma concepção romântica de inspiração. Há um trabalho precedente de acumulação, ou seja, de inventariar um arsenal com o qual operará sua máquina de guerra. Dessa materialidade inventariada, de diferentes domínios de saber, diferentes afecções, Deleuze realiza um exercício minucioso de bricolagem; de corte e colagem; de arranjo, permutação e combinação. O autor evidencia pormenores e excessos, às falhas na sedimentação, aos desequilíbrios e heterogeneidades, àquilo que muitas vezes seria tomado como sobra. Assim, Deleuze desvia-se das pretensas intenções originais, da condenação retórica da Verdade, dos modelos do senso comum e do bom senso, atualizando por diferenciação aquilo que lê.

Esse exercício consiste numa estratégia transtextual operada por um trabalho palimpsesto de criação. O que precede permanece ali, não como legado a-histórico, mas como herança viva, atualizada, diferençada, movimentada. Nisso consiste seu processo de criação: ecos, reverberações, tangenciamentos, conexões de partes até então não comunicantes.

Propomo-nos a pensar a minorização de um currículo de matemáticas através desse procedimento e seguimos no exercício de inquirição. Como elaborar novas cadeias de interpretação, sempre fissuradas, por onde passa ar e por onde o acaso se infiltra? De que maneira as produções de sentidos outros impactam na aula e os que estão ali com ela dispostos - professora, alunos, saberes? Quais outras áreas, saberes, conhecimentos, experiências podem adentrar no planejamento de aulas de matemáticas e num currículo que deseje o aumento da potência dos corpos que se encontram na aula? Como efetivar tangenciamentos, no campo do currículo, entre as matemáticas e outras áreas, estabelecendo contato nas múltiplas nas fronteiras, sem objetivos interdisciplinares, mas no intuito de criar condições de possibilidade para a invenção de novos modos de subjetivação e de resistência à interpretose?

Ensinar matemáticas passa pela reprodução de fórmulas, definições, axiomas que são próprios dessa disciplina, mas não exige a permanência nesse lugar. Preparar aulas consiste num trabalho de estabelecimento de articulações entre saberes didáticos, curriculares, científicos, legislativos, literários, experimentados, vividos, rachando-os: abrindo-os a novas relações, intervenções, interpretações, atualizações. Trata-se de um exercício de criação e experimentação que passa por um procedimento de arranjamentos e de positivação dos pormenores, de menorização, ao atentar aos gestos, aos olhares, aos movimentos, aos mais variados vetores constitutivos da aula, às interferências de temperatura, tempo, luz, pressão, umidade, cheiros, tensões, pulsões... aproximando-se de uma política experimental de inspiração deleuziana que questiona "quais os efeitos disso que lemos?”.

Não se trata apenas de buscar incluir outras formas de produção de matemáticas, outros modelos de racionalidade além da epistemologia eurocentrada. Menos ainda, trata-se de uma exclusão ou negação 
de conhecimentos já dispostos. Mas, antes, de inspiração no procedimento que vemos em Deleuze, em que o extrafilosófico serve como matéria de encontro para pensar a filosofia. Assim, sugerimos tomar o extracientífico, o não-pedagógico, para pensar currículos, saberes, fazeres, em que a ética e a política da potência de agir seja crivo para a variabilidade da docência e dos currículos.

Trata-se, ainda, da criação de um currículo que não exclui o corpo, que não naturaliza práticas de injunção social, de vigilância sobre os corpos ali dispostos, objetificando-os. Para além do uso de dedos para contagem ou de partes do corpo para a realização de medições, trata-se de engendrar um currículo que comporte, em aulas de matemática, singularidades incorpóreas que se atualizam nos corpos que ali estão. Quais as referências, por mais exíguas que sejam, a um corpo no Currículo de Matemática? A menos que trate de um sujeito psicologizado, de um aprendiz epistemológico ou de ferramenta de contagem ou medição, o corpo parece não adentrar nas discussões curriculares em matemáticas.

Quais os aparatos de controle implicados na maneira hegemônica de conduzir-se numa aula de matemática? Quais fazeres e sentires preocupam-se, no Currículo, com a potência de agir da aluna, do aluno, da professora que compõem uma aula? As diferenças se atualizam em pontos de aplicação, a diferençação diferencial necessita de um corpo. Como cavar brechas, constituir práticas, um ethos, na elaboração de um currículo que se preocupa com processos de autodiferenciação, de efetuação de singularidades? Quais afecções transpassam os corpos que se encontram na escola, na aula, nas relações que se estabelecem? Como elaborar caminhos que desviem dos processos massificantes de unificação e nivelamento senão inserindo ritmos, velocidades, intensidades que transpassam o corpo?

As forças de conservação do Currículo procedem por eleição e fortalecimento de verdades e certezas, mais do que pela inquirição do que está posto; por linearidade, mais do que pela fragmentação; por maioridade, mais do que pela minoração; por decalque, mais do que por combinação; pela estática, mais que pelo dinamismo; por fronteiras, limites e segregações, mais do que por conexão e arranjamento; por normatização, Lei, regras, parâmetros, mais do que por subjetividades e intensidades. Como resistência, inventamos e inventariamos modos outros de conduzir nossas pesquisas, nossas aulas, nossas relações com currículos, saberes, sentires. Adentramos no terreno da Diferença deleuziana (DELEUZE, 2006), num modo interrogativo e contingente de estabelecer vinculações. "As diferenças, tornadas "infinitamente pequenas", se farão em uma única e mesma matéria que servirá de expressão como potência incorpórea, mas que servirá igualmente de conteúdo como corporeidade sem limites" (DELEUZE; GUATTARI, 1995, p. 57).

\section{Um Porvir: (In)Conclusões}

Assume-se uma atitude de resistência às forças de conservação no desejo de produção de outros modos de ler o Currículo (de Matemática). Modos menos dogmáticos, morais, transcendentes, utilitaristas. Trata-se de maquinar uma aula e maquinar novas leituras e engendramentos curriculares, por 
contágios. Consiste numa atividade de colecionamento e corte, de combinação de segmentaridades maleáveis, de acúmulo e dispersão. "É por isso que devemos distinguir: o majoritário como sistema homogêneo e constante, as minorias como subsistemas, e o minoritário como devir potencial e criado, criativo" (DELEUZE; GUATTARI, 1995, p. 52).

Trazemos à discussão curricular o que nos diz Guattari em As três ecologias: “Tratar-se-á de dar conta dessas práticas menos em termos de verdade científica que em função de sua eficácia estéticoexistencial. Que foi posto em funcionamento aqui?” (GUATTARI, 2012, p. 40). Operamos um estilo para resistir, conjugamos elementos de minoria para fazer vazar, inquirimos para abrir fendas, colecionamos referências e as articulamos para criar. Peneiramos currículos e aulas pelas afecções que nos interpelam e questionamos: o que nos dá fôlego para mais?

\section{REFERÊNCIAS}

ABBAGnANO, Nicola. Dicionário de Filosofia. Tradução de Alfredo Bosi. 6. ed. São Paulo: WMF Martins Fontes, 2012.

ADÓ, Máximo Daniel Lamela; CORAZZA, Sandra Mara; CAMPOS, Maria Idalina Krause. Processos tradutores em pesquisa em Educação: Projeto Escrileitura. Educação e Pesquisa. São Paulo, v. 43, n. 4, p. 1163-1178, out/dez 2017.

CAMPOS, Haroldo de. A reoperação do texto. São Paulo: Perspectiva, 2013.

CAMPOS, Haroldo de. Transcriação. TÁPIA, Marcelo; NÓBREGA, Telma Médici (Orgs). São Paulo: Perspectiva, 2015.

COSTA, Annita Malufe. Estilo e repetição: Deleuze e algumas poéticas contemporâneas. Caderno de Letras (UFRJ), n. 26 - jun. 2010.

DELEUZE, Gilles. Abecedário de Gilles Deleuze. Entrevista concedida a Claire Parnet, 1988. Disponível em www.youtube.com/watch?v=mkaoIcdiaMw Visitado dia 24/03/2021

DELEUZE, Gilles. Diferença e Repetição. Trad. Luiz Orlandi e Roberto Machado. Rio de Janeiro: Graal, 2ed 2006.

DELEUZE, Gilles; GUATTARI, Félix. Mil platôs - capitalismo e esquizofrenia. Vol. 2. Tradução Ana Lúcia de Oliveira e Lúcia Cláudia Leão. Rio de Janeiro: Ed. 34, 1995.

DELEUZE, Gilles; GUATTARI, Félix. Kafka: por uma literatura menor. Tradução Cíntia Vieira da Silva. 1. Ed. 3. reimp. Belo Horizonte: Autêntica Editora, 2017.

GALLO, Sílvio. Em torno de uma Educação Menor. Revista Educação e Realidade. 2002, p. 169-178. GALLO, Sílvio. Deleuze \& Educação. Belo Horizonte. Autêntica, 2013. 
GUATTARI, Félix. As três ecologias. Tradução Maria Cristina f. Bittencourt. 21 a ed. Campinas, SP: Papirus, 2012.

MACHADO, Nilson José. Matemática e língua materna: análise de uma impregnação mútua. Ged. São Paulo: Cortez, 2011.

MUNHOZ, Angélica; ADÓ, Máximo Daniel Lamela. Criação poética e currículo da diferença. Revista Pro.posições. v. 28, suppl. 1, 2017.

NIETZSCHE, Friedrich Wilhelm. A Gaia Ciência. Tradução, notas e posfácio de Paulo César de Souza. São Paulo: Companhia das Letras, 2001.

NIETZSCHE, Friedrich Wilhelm. Humano, demasiado humano: um livro para espíritos livres. Tradução, notas e posfácio de Paulo César de Souza. São Paulo: Companhia das Letras, 2005.

ROSA, Francis Mary Soares Correia da. A literatura menor em Deleuze e Guattari: por uma educação menor. Educação (UFSM), v.41, n.3, p. 685-696, 2016. 